\title{
Absceso epidural espinal: caso clínico pediátrico
} Pediatric case report: Spinal epidural abscess

\author{
Dr. Mauricio Pons ${ }^{a}$, Dra. Leila Pérez $z^{a}$ y Dr. Facundo Juáreza
}

\begin{abstract}
RESUMEN
El absceso epidural espinal, una patología poco frecuente, presenta una incidencia de un caso cada 100000 individuos, y se observa un aumento debido al incremento de factores de riesgo, tales como diabetes mellitus, anomalías espinales, tatuajes, acupuntura, analgesia epidural, sumado a una mayor disponibilidad de métodos de imágenes. Es una colección purulenta localizada entre la duramadre y el canal medular. Los gérmenes más comunes son Staphylococcus aureus y bacterias Gram-negativas. Sin tratamiento oportuno, evoluciona a la compresión medular y secuelas neurológicas permanentes.

Una niña de 11 años se presentó con fiebre de 48 horas de evolución, dolor lumbar izquierdo, marcha antálgica con envaramiento lumbar. El examen neurológico era normal. Sobre los miembros inferiores, se observaban lesiones ampollares destechadas. La resonancia nuclear magnética mostró una imagen compatible con absceso epidural espinal. Evolucionó favorablemente. El tratamiento consistió en drenaje quirúrgico y antibióticos por 6 semanas. Del cultivo del material obtenido, creció Staphylococcus aureus meticilino sensible.

Palabras clave: absceso epidural, pediatría.
\end{abstract}

\begin{abstract}
Spinal epidural abscess is an uncommon pathology. It has an incidence of one case per 100000 individuals. An increase is observed due to the raise of risk factors such as diabetes mellitus, spinal abnormalities, tattoos, acupuncture, epidural analgesia, and a greater availability of imaging methods. It is a purulent collection located between the dura and the medullary canal. The most common germs are Staphylococcus aureus and Gram-negative bacteria. Without timely treatment, it evolves to medullary compression and permanent neurological sequelae. An 11-year-old girl was admitted with fever of $48 \mathrm{hs}$ evolution, left lower back pain, antalgic gait with lumbar stiffness. Neurological examination was normal. Blunt blistering lesions were observed on lower limbs. Magnetic resonance imaging showed an image compatible with spinal epidural abscess. The evolution was favorable. Treatment consisted of surgical drainage and antibiotics for 6 weeks. From the culture of the material obtained, methicillin-sensitive Staphylococcus aureus was isolated. Key words: epidural abscess, pediatrics.
\end{abstract}

http:/ / dx.doi.org/10.5546/ aap.2017.e146

Cómo citar: Pons M, Pérez L, Juárez F. Absceso epidural espinal: caso clínico pediátrico Arch Argent Pediatr 2017;115(3):e146-e149.

a. Hospital Interzonal Especializado Materno Infantil "Don Victorio Tetamanti", Mar del Plata.

Correspondencia:

Dr. Mauricio Pons, mauriciopons@hotmail.com

Financiamiento: Ninguno.

Conflicto de intereses: Ninguno que declarar.

Recibido: 10-5-2016

Aceptado: 16-1-2017

\section{INTRODUCCIÓN}

El absceso epidural espinal es una patología poco frecuente, que presenta una incidencia de un caso cada 100000 individuos. ${ }^{1}$ Se observa, actualmente, un aumento debido al incremento de los factores de riesgo, tales como diabetes mellitus, anomalías espinales, tatuajes, acupuntura, analgesia epidural, sumado a una mayor disponibilidad de métodos de imágenes, que aumentan las posibilidades de establecer el diagnóstico. ${ }^{1}$ Se caracteriza por una colección purulenta que se localiza entre la duramadre y el canal medular. El Staphylococcus aureus es el agente etiológico más frecuente y llega a dicho espacio por extensión directa o diseminación hematógena desde un foco lejano. ${ }^{2}$

Se describe a una niña con absceso epidural espinal internada en nuestro Hospital.

\section{Reporte del caso}

Niña de 11 años de edad, sin antecedentes patológicos familiares ni personales de relevancia, vacunación completa para su edad, eutrófica, que consultó al sector de Emergencias de nuestro Hospital por presentar dolor lumbar y registro febril de $38{ }^{\circ} \mathrm{C}$ de 48 horas de evolución. Se indicó analgesia y pautas de consulta, sin solicitar estudios de laboratorio.

Cuarenta y ocho horas después, por aumento del dolor y por persistir febril, realizó una segunda consulta al sector de Emergencias, donde se decidió su internación.

$\mathrm{Al}$ ingresar, la paciente se presentaba febril, $38,5^{\circ} \mathrm{C}$, en regular estado general, con dolor en la región lumbar izquierda continuo, con escasa respuesta al tratamiento analgésico, que se exacerbaba ante la compresión paravertebral izquierda. La marcha era antálgica, con envaramiento lumbar e imposibilidad para realizar la maniobra de Adams.

Al momento del examen neurológico, la coordinación, la movilidad, la fuerza muscular, el tono y la sensibilidad de los miembros inferiores estaban conservados. Los reflejos de estiramiento de los miembros inferiores y la función esfinteriana eran normales. El resto del examen neurológico tampoco presentaba alteraciones. 
En la piel, sobre los miembros inferiores, se observaban múltiples lesiones ampollares destechadas de $0,5 \mathrm{~cm}$ de diámetro de 4 días de evolución, sin signos inflamatorios actuales, con aspecto de picaduras de insecto (Figura 1).

No se registraron alteraciones en el resto del examen físico y no volvió a presentar fiebre durante la internación, probablemente, por efecto de antipiréticos y buena respuesta al antibiótico administrado.

Se sospechó infección en la región retroperitoneal (absceso de psoas, absceso perirrenal, absceso epidural), por lo que se solicitó hemograma y eritrosedimentación, hemocultivos, orina completa, radiografía lumbar, ecografía lumbar de partes blandas. Los estudios no resultaron concluyentes, por lo que se solicitó una resonancia magnética nuclear (RMN) toracolumbar.

FIGURA 1. Lesiones en los miembros inferiores, sin signos inflamatorios actuales

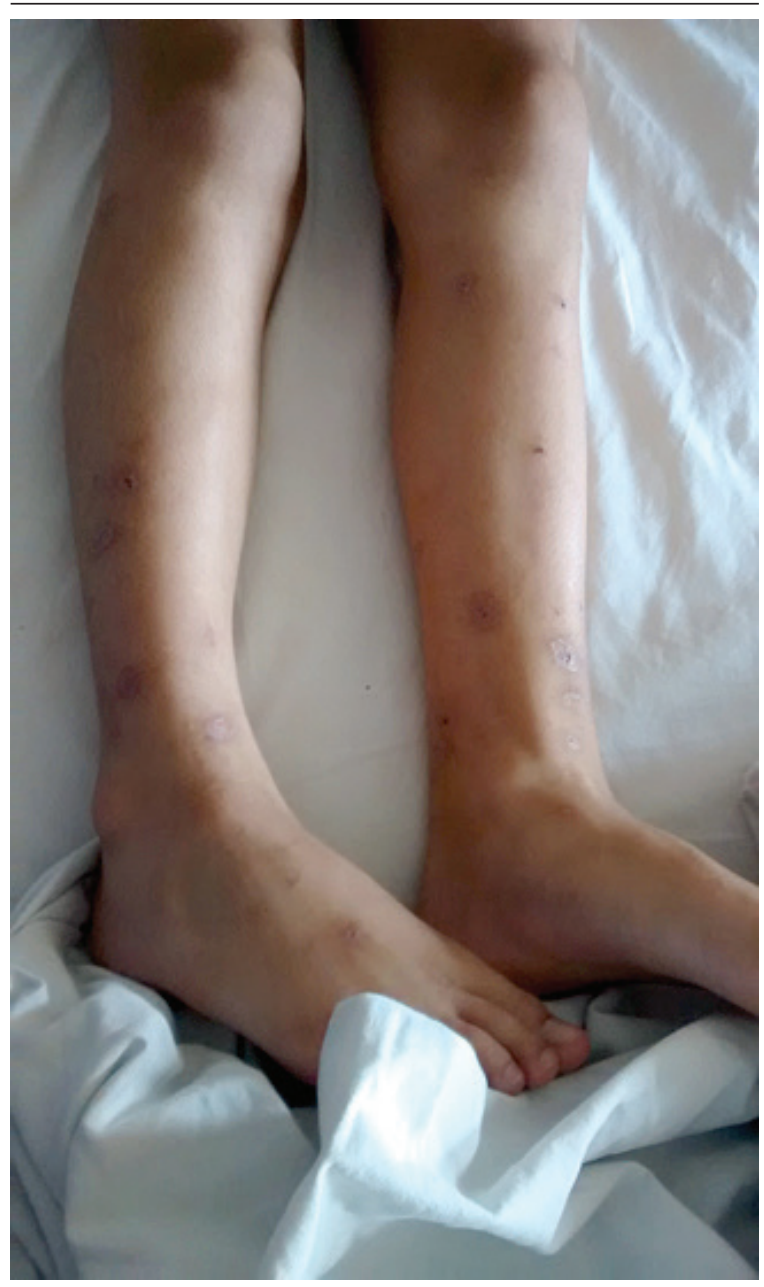

Se inició un tratamiento empírico con $40 \mathrm{mg} /$ $\mathrm{kg} /$ día de clindamicina endovenosa cada 8 horas, con la toma previa de hemocultivos.

El resultado del hemograma inicial fue 16100 glóbulos blancos (neutrófilos segmentados: $83 \%$; linfocitos: $15 \%$; monocitos: $2 \%$ ), orina completa con sedimento normal. Eritrosedimentación: $30 \mathrm{~mm}$; hematocrito: 39\%; hemoglobina: 13,2 g/dl. Los hemocultivos fueron negativos. La RMN informó, por detrás de los cuerpos vertebrales dorsal 8, dorsal 9, dorsal 10, una imagen alargada extradural de, aproximadamente, $5 \times 8 \mathrm{~cm}$, hiperintensa en las secuencias T1 y T2, que presentó un intenso realce tras la inyección de gadolinio. Se observaba compresión de la cara posterior del saco tecal medular espinal en el mencionado nivel (Figura 2).

Como consecuencia de este hallazgo, ante la sospecha de un absceso, la paciente fue intervenida para drenar el contenido. Se obtuvo material purulento, cuyo cultivo fue positivo para Staphylococcus aureus meticilino sensible. Se cambió la medicación a cefazolina, la cual se administró por 6 semanas.

FIGURA 2. Resonancia magnética nuclear con gadolinio en la que se observa colección epidural a nivel de D8, D9 y D10 (flecha)

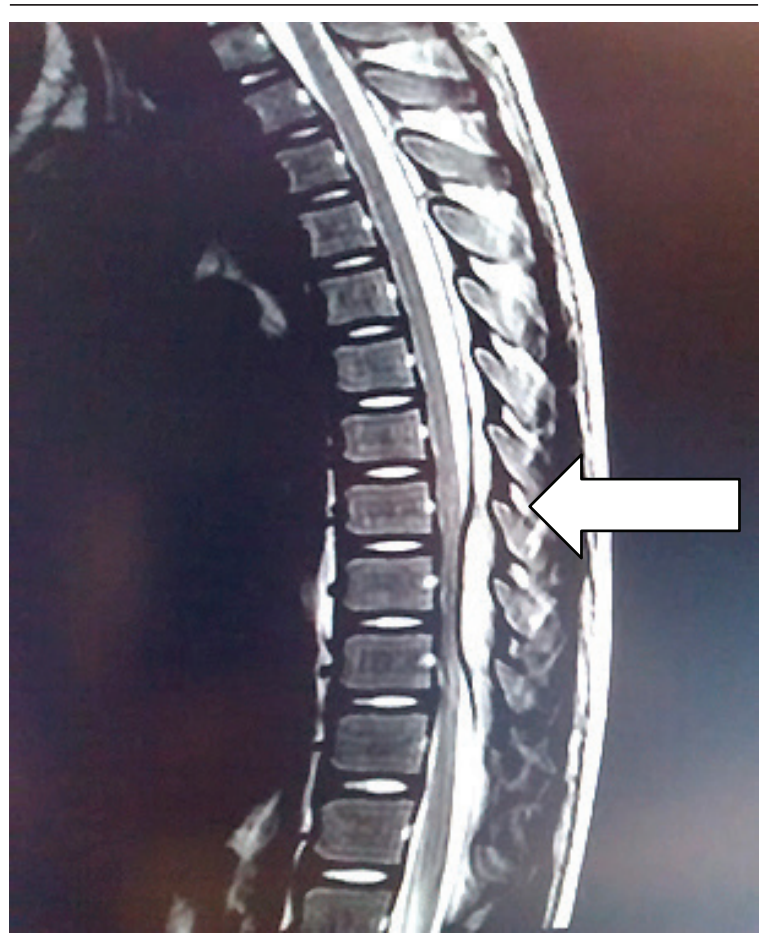


A las 48 h del drenaje quirúrgico, se observó franca mejoría del estado de la niña, que permaneció afebril, sin dolor y recuperó, en la región lumbar, la lordosis y movilidad fisiológicas.

Se realizaron controles semanales de hemograma y eritrosedimentación, y se observó su paulatina normalización. La eritrosedimentación, en la primera semana, disminuyó a $27 \mathrm{~mm}$ y luego a $23 \mathrm{~mm}$. Debido a la buena evolución clínica, se indicó un curso de 4 semanas de tratamiento endovenoso y, posteriormente, dos semanas de cefalexina por vía oral. Se obtuvo una nueva RMN al final del tratamiento, que mostró la completa resolución de la colección.

\section{DISCUSIÓN}

El absceso epidural espinal es una infección infrecuente que requiere un diagnóstico precoz y tratamiento oportuno para evitar secuelas graves, tales como disfunción vesical e intestinal y paraplejia.

En nuestra paciente, la presentación clínica se limitaba a dolor lumbar y fiebre, sin signos neurológicos. Llama la atención que, en la primera consulta al sector de Emergencias, no se haya realizado un mínimo screening para hallar la fuente de infección, ya que los síntomas de inicio podrían corresponderse con infección del tracto urinario y la interpretación de los análisis de laboratorio abriría un abanico de posibilidades diagnósticas que incluirían la afección que nos ocupa.

En el absceso epidural, la bibliografía establece una secuencia de estadios para la progresión de los síntomas y los hallazgos físicos. Estadio 1: dolor de espalda a nivel de las vértebras afectadas; estadio 2: dolor radicular desde el área espinal involucrada; estadio 3: debilidad motora, déficit sensitivo, disfunción vesical e intestinal; estadio 4: parálisis. La infección epidural puede producir lesión de la médula espinal vía compresión mecánica directa $\mathrm{o}$, indirectamente, por trombosis del plexo venoso espinal. Nuestra paciente se presentó en estadio 1. El dolor de espalda se presenta en el $75 \%$; la fiebre, en el $50 \%$; y el déficit neurológico, en alrededor del 30\%. Estos son los 3 síntomas más comunes. ${ }^{1,3,4}$ Pero esta tríada clásica se presenta rara vez, ${ }^{5}$ ya que, habitualmente, el diagnóstico puede ser establecido antes de la aparición de los signos neurológicos.

El tiempo de progresión de un estadio a otro es muy variable y puede desarrollarse de un déficit neurológico leve a una paraplejia en horas o días. ${ }^{6}$

Para la adquisición del empiema epidural, existen múltiples condiciones predisponentes, tales como enfermedades de base (diabetes mellitus, infección por virus de la inmunodeficiencia humana-VIH-), anomalías espinales, tatuajes, acupuntura, analgesia epidural, trauma e infecciones de la piel y las partes blandas, entre otros. ${ }^{7,8} \mathrm{El}$ arribo del germen al sitio de infección se logra a través de la vía hematógena o por contigüidad; la primera es la más frecuente en la población pediátrica. ${ }^{9}$

Se supone que la puerta de entrada para la infección de nuestra paciente fueron las lesiones ampollares de las piernas con posterior diseminación hematógena, a pesar de presentar hemocultivos negativos. En algunos casos, la fuente de infección no es identificable. Llama la atención la escasa elevación de la eritrosedimentación. La proteína $C$ reactiva, biomarcador más sensible que la eritrosedimentación, no pudo realizarse.

Dentro de los agentes etiológicos, el Staphylococcus aureus se aísla en alrededor de $66 \%$ de los casos. ${ }^{1,3,10}$ Se observa un aumento de la prevalencia de Staphylococcus aureus meticilino resistente (SAMR) en niños sin factores de riesgo. ${ }^{11,12}$ No obstante, la revisión de la literatura hecha por Auletta et al. indica un alto rango de infección por Staphylococcus aureus meticilino sensible, como se observó en nuestra paciente. ${ }^{13}$ Patógenos menos comunes incluyen estafilococo coagulasa negativo y bacterias Gram-negativas, particularmente, Escherichia coli y Pseudomonas. Raramente, puede estar causado por bacterias anaerobias, agentes de actinomicosis o nocardiosis, micobacterias (tuberculosa y no tuberculosa), hongos o parásitos. ${ }^{14}$

En cuanto al diagnóstico, el método de elección es la RMN con gadolinio porque brinda detalles de extensión, útiles a la hora del drenaje quirúrgico. La tomografía axial computada con contraste también puede ser usada.

El tratamiento, típicamente, consiste en la descompresión quirúrgica y el drenaje en combinación con varias semanas de antibióticos, ya que se trata de una región anatómica con riesgo de compromiso óseo y del sistema nervioso central (SNC). En la elección empírica del antibiótico, debe tenerse en cuenta el SAMR. El pronóstico está en relación con el estadio clínico al momento de la presentación y con la precocidad del diagnóstico y del tratamiento. ${ }^{15}$ 


\section{REFERENCIAS}

1. Aycan A, Aktas OY, Guzey FK, et al. Rapidly Progressive Spontaneous Spinal Epidural Abscess. Case Rep Infect Dis 2016;2016:7958291.

2. Pereira CE, Lynch JC. Spinal Epidural abscess: Analysis of 24 cases. Surg Neurol 2005;63(Suppl 1):S26-9.

3. Grewal S, Hocking G, Wild Smith JA. Epidural Abscesses. Br J Anaesth 2006;96(3):292-302.

4. Rigamonti D, Liem L, Sampath P, et al. Spinal epidural abscess: Contemporary Trends in etiology, evaluation and management. Surg Neurol 1999;52(2):189-96.

5. Figueroa L, Lorenzo M, Martínez D, et al. Absceso epidural espinal: Nuestra experiencia en un año. Rev Argent Neurocir 2006; 20(1):37-40.

6. Reisaus E, Waldbaur H, Seeling W. Spinal Epidural abscess: a meta-analysis of 915 patients. Neurosurg Rev 2000;23(4):175-204.

7. Akalan N, Ozgen T. Infection as a cause of spinal cord compression: a review of 36 spinal epidural abscess cases. Acta Neurochir (Wien) 2000;142(1):17-23.

8. KhanSH,Hussain M, Griebel R, etal.Comparison of primary and secondary spinal epidural abscesses: A retrospective analysis of 29 cases. Surg Neurol 2003;59(1):28-33.
9. Darouiche RO, Hamill RJ, Greenberg SB, et al. Bacterial spinal epidural abscess: review of 43 cases and literature survey. Medicine (Baltimore) 1992;71(6):369-85.

10. Auletta JJ, John CC. Spinal epidural abscesses in children: a 15-year experience and review of the literature. Clin Infect Dis 2001;32(1):9-16.

11. Darouiche RO. Spinal epidural abscess. $N$ Eng J Med 2006;355(19): 2012-20.

12. Herold BC, Immergluck LC, Maranan MC, et al. Community-acquired methicillin resistantStaphylococcus aureus in children with no identified predisposing risk. JAMA 1998; 279(8):593-8.

13. Suggs AH, Marana MC, Boyle-Vavra S, et al. Methicillinresistant and borderline methicillin-resistant asymptomatic Staphylococcus Aureus colonization in children without identifiable risk factor. Pediatr Infect Dis J 1999;18(5):410-4.

14. Hawkins M, Bolton M. Pediatric Spinal Epidural Abscess: A 9-Year Institutional Review and Review of the Literature. Pediatrics 2013;132(6):e1680-5.

15. Davis DP, Wold RM, Patel RJ, et al. The clinical presentation and impact of diagnostic delays on emergency department patients with spinal epidural abscess. J Emerg Med 2004;26(3):285-91. 